\title{
Pemanfaatan Big Data Dalam Era Teknologi 5.0
}

\author{
Luluk Setyowati (1), Deni Nasir Ahmad(2)* \\ (1)Pendidikan Fisika, Universitas Indraprasta PGRI \\ (2)Pendidikan Matematika, Universitas Indraprasta PGRI \\ Universitas Indraprasta PGRI. Jl. Nangka No. 58 B, Tanjung Barat. Jaksel. \\ *Email : deninasirahmad@gmail.com*
}

\begin{abstract}
Society era 5.0 is a conception of society that is already literate to Information and Communication Technology (ICT). The purpose of community service activities is to provide information to participants that there is a positive movement in the era of social communication from the 4.0 era to the 5.0 era. The methods used in this activity are: a. Direct observation, namely the servant directly comes to the service location to obtain data. $b$. Carry out community service activities with an online system in providing material for community service activities. $c$. Conducting evaluations and sharing together to find mutual agreement in making environmental improvements. The service activities that have been carried out provide a benefit for students who will enter the community regarding technological developments in 5.0. The conclusion of service activities is that the development of information 5.0 is the basis for improving the community's economy in order to move towards a modern society.
\end{abstract}

Keywords: Big Data, Era 5.0, Information Technology

\begin{abstract}
Abstrak
Masyarakat era 5.0 merupakan konsepsi masyarakat yang sudah melek terhadap Teknologi Informasi dan Komunikasi (TIK). Tujuan dari kegiatan pengabdian kepada masyarakat memberikan informasi kepada para peserta bahwa terjadinya gerak positif era komunikasi secara sosial dari era 4.0 menuju era 5.0. Metode yang dilakukan dalam kegiatan ini yaitu : a. Observasi langsung yakni pengabdi langsung datang ke lokasi pengabdian untuk memperolah data. b. Melakukan kegiatan pengabdian masyarakat dengan sistem daring dalam pemberian materi kegiatan pengabdian masyarakat. c. Melakukan evaluasi dan shering bersama untuk menemukan kesepakatan bersama dalam melakukan perbaikan lingkungan. Kegiatan pengabdian yang telah dilakukan memberikan suatu manfaat bagi mahasiswa yang akan terjun kedalam masyarakat mengenai perkembangan teknologi pada 5.0. Kesimpulan kegiatan pengabdian yaitu Perkembangan informasi 5.0 merupakan dasar peningkatan perekonomian masyarakat guna menuju masyarakat modern.
\end{abstract}

Kata Kunci : Big Data, Era 5.0, Teknologi Informasi

\section{PENDAHULUAN}

Masyarakat era 5.0 ialah konsepsi masyarakat yang telah melek terhadap Teknologi Informasi dan Komunikasi ( TIK ). Dimana saat sebelum masa 5.0 sudah terdapatnya pergantian dalam revolusi industri 4.0 dimana mengganti hidup dan kerja manusia secara fundamental. Konsep revolusi industri 4.0 dan society 5.0 tidak mempunyai perbandingan yang jauh, ialah revolusi industri 4.0 memakai kecerdasan buatan (artificial intellegent) sebaliknya society 5.0 memfokuskan kepada komponen manusianya (Puspita et al. 2020). Menurut Bahrin (Hendarsyah 2019) menarangkan kalau teknologi yang berhubungan dengan industri 4.0 merupakan " The Internet of Things ( IOT )" berperan guna menghubungkan seluruh fitur komputasi memakai teknologi tertentu. Bahkan di era teknologi informasi sekarang ini teknonlogi memberikan kemudahan dalam berbagai kegiatan (Yandra:2018). Berbeda dengan revolusi industri sebelumnya ialah generasi masa 1.0 hingga dengan masa 3.0, revolusi industri generasi 4.0 ini mempunyai skala, ruang lingkup, serta kompleksitas yang 
ABDINE: Jurnal Pengabdian Kepada Masyarakat Vol.1, No.2, Desember 2021,Hal.117-122 p-ISSN 2798-2882, e-ISSN 2798-2890

lebih luas. Kemajuan teknologi baru yang mengintegrasikan dunia fisik, digital, dan biologis sudah mempengaruhi seluruh disiplin ilmu, ekonomi, industri, serta pemerintah. Mengizinkan piranti berbicara serta berhubungan satu sama lain dengan pengontrolan yang terpusat. Peran perguruan tinggi yang memiliki tugas penting untuk membangun Sumber Daya Manusia (SDM) Indonesia produktif, kreatif dan inovatif berjiwa innovator dan technopreneur dalam menyongsong era Society 5.0 sehingga diharapkan setiap perguruan tinggi harus mampu melakukan akses dan mutu pendidikan tinggi melalui proses belajar-mengajar yang bisa se-fleksibel mungkin dengan kualitas tinggi melalui perubahan kurikulum atau metode pembelajaran (Marlinah 2019).

Dimana pada pertumbuhan teknologi masa 4 . 0 ialah a. Cybersecurity, untuk industri 4 . 0 sangat berarti buat menanggulangi permasalahan ancaman keamanan siber yang bertambah secara signifikan dengan meningkatnya konektivitas serta pemakaian standar protokol komunikasi sebab guna melindungi privacy informasi pengguna; b. The cloud, berguna dalam menganalisa serta mengambil keputusan secara langsung guna meningkatnya kinerja teknologi, informasi serta fungsionalitas hingga disebarkan ke cloud / awan, agar lebih banyak layanan berbasis informasi guna sistem penciptaan sehingga menciptakan perolehan informasi data posisi industri lebih banyak lagi ; c. Big informasi analytics, membolehkan pengumpulan serta penilaian informasi yang komprehensif dari bermacam sumber serta pelanggan guna menunjang pengambilan keputusan langsung, memaksimalkan mutu penciptaan, menghemat tenaga serta tingkatkan layanan peralatan ; d. Horizontal and vertical system integration, integrasi sistem horisontal dan vertikal di antara industri, kementerian, tugas dan keahlian akan jadi lebih kohesif, bersamaan lintas industri, jaringan integrasi data universal berkembang dan memungkinkan rantai nilai yang betul - betul otomatis ; e . Augmented reality, bisa menunjang bermacam layanan, semacam memilah suku cadang di gudang serta mengirim instruksi revisi lewat fitur seluler ; f . Additive manufacturing ( $3 D$ printing ), bisa menciptakan beberapa produk yang disesuaikan semacam desain yang kompleks serta ringan, berperforma besar serta mengurangi jarak pengangkutan dan persediaan ; g. Simulation, menggunakan informasi realtime guna mencerminkan realitas dalam model virtual, yang mencakup semacam mesin, produk dan manusia sehingga memungkinkan operator untuk menguji serta memaksimalkan pengaturan perlengkapan guna penciptaan selanjutnya serta bisa kurangi waktu pengaturan alat serta tingkatkan mutu produk; h. Robots, ialah mesin lebih mandiri, fleksibel dan kooperatif, mereka hendak berhubungan satu sama lain dan dapat bekerja dengan nyaman bersama manusia, kemudian belajar dari mereka dan mempunyai kelebihan kalau Robot lebih murah biayanya dan mempunyai jangkauan keahlian yang lebih besar (Hendarsyah 2019).

Dalam Industri 4.0 memerlukan tenaga kerja yang mempunyai keahlian dalam literasi digital, literasi teknologi dan literasi manusia dimana dengan membekali lulusan dengan ketiga literasi tersebut melalui revitalisasi chronosystem yang meliputi sistem pendidikan, satuan pendidikan, peserta didik, dan pendidik serta tenaga kependidikan (Muhammad Yahya 2018). Di dalam bidang pembelajaran pada masa generasi 4.0 ialah fenomena yang direspon bersumber pada kebutuhan revolusi industri keempat ialah di mana manusia dan mesin diselaraskan guna memperoleh solusi, memecahkan permasalahan, dan tentu saja menciptakan kemungkinan inovasi baru. Sistem e-learning merupakan mutlak dibutuhkan buat mengestimasi perkembangan jaman dengan support teknologi informasi dimana seluruhnya mengarah ke masa digital, baik mekanisme ataupun konten. Beberapa manfaat dari $e$ learning menurut Rohmah (Ma'rifatullah et al. 2020), yakni (1) dengan adanya $e$ learning maka dapat mempersingkat waktu pendidikan serta membuat anggaran riset lebih murah; (2) E-learning memudahkan interaksi antara peserta didik dengan bahan 
materi; ( 3 ) Peserta didik bisa saling berbagi informasi serta bisa mengakses bahan bahan belajar setiap saat serta berulang - ulang, dengan keadaan yang demikian itu peserta didik dapat lebih memantapkan penguasaannya terhadap materi pembelajaran. Berdasarkan hasil pelatihan e-learning menunjukkan bahwa pembelajaran daring menggunakan e-Learning berbasis edmodo mampu mengoptimalkan peningkatan aktivitas belajar peserta didik dari sebelumnya (Gellysa Urva et al. 2021).

Berikutnya teknologi saat ini ini sudah akan memasukin era 5.0 karenanya terjadi pergantian teknologi era 4.0 mengarah teknologi sosial era 5.0 . Dimana manusia menggunakan teknologi untuk kesejahteraan manusia bukan menghasilkan teknologi sebagai suatu kekuatan ataupun dengan kata lain era teknologi 5.0 menawarkan kepada masyarakat dimana teknologi berpusat pada manusia agar dapat menciptakan proporsional antara kemajuan ekonomi dengan penyelesaian permasalahan sosial lewat sistem yang sangat menghubungkan melalui dunia maya dan dunia nyata. Teknologi era 5.0 atau Society 5.0 merupakan era di mana seluruh teknologi merupakan bagian dari manusia itu sendiri, internet bukan cuma selaku informasi melainkan untuk menjalani kehidupan sehingga perkembangan teknologi dapat meminimalisir terdapatnya kesenjangan pada manusia serta permasalahan ekonomi pada kemudian hari. Penggunaan bahasa pemograman PHP dan Mysql sudah sangat sering digunakan untuk mempermudah pekerjaan manusia (Desyanti, Susy Sri Handayani, Wetri Febrina 2021). Berdasarkan hasil penelitian bahwa perilaku masyarakat lebih senang dengan memanfatkan teknologi dalam memenuhi kebutuhan dengan segala kemudahan, salah satu bentuk mengalirnya era Revolusi Industri dan Society 5.0 di Indonesia yakni e-commerce hasilnya bahwa $44.8 \%$ hasil survey menunjukkan transaksi dengan e-commerce lebih diminati karena pangsa pasar lebih luas, lebih memberikan kemudahan, tanpa adanya batasan waktu dan perbandingan harga antar produk dapat lebih akurat (Mumtaha \& Khoiri 2019).

Masyarakat yang literat dengan kecakapan hidup, akan dapat mengetahui suatu realitas dengan pemahaman yang utuh dimana masyarakat mampu bertindak kreatif serta bersikap kritis terhadap suatu fenomena (Agustini \& Sucihati 2020). Dimana Society 5.0 merupakan masyarakat yang dapat menuntaskan bermacam tantangan serta kasus sosial dengan menggunakan bermacam inovasi yang lahir di masa Revolusi industri 4.0 semacam Internet on Things (internet untuk seluruh suatu), Artificial Intelligence (kecerdasan buatan), Big Data (data dalam jumlah besar), dan robot guna meningkatkan mutu hidup manusia (Puspita et al. 2020). Dari kedua pendapat tersebut jelas bahwa perkembangan era dari 4.0 menjadi society 5.0 mendorong masyarakat untuk mampu beradaptasi dan berinovasi. Dampak dari perkembangan tersebut, masyarakat harus mampu menjalankan teknologi informasi yang ada karena teknologi informasi terus tumbuh dan berkembang sejalan dengan perkembangan teknologi digital (Ellitan 2020).

Dari uraian tersebut jelas kalau pemanfaatan teknologi yang mulai beralih dari era teknologi 4.0 menjadi era teknologi 5.0 dibutuhkan suatu keahlian serta penginformasian menjadikan setiap pembelajaran membutuhkan suatu literasi dalam tiap kegiatannya. Oleh karena itu tim pengabdi melaksanakan suatu aktivitas berbentuk penginformasian dan sosialisasi perkembangan teknologi informasi berbasis data atau big data sebagai suatu literasi keahlian dalam produk pembelajaran. Sehingga tujuan dari kami tim pengabdi adalah memberikan informasi dan sosialisasi penggunaan teknologi era teknologi 5.0 dalam pemerolehan literasi dalam pembelajaran.

\section{METODE}

Metode yang dilakukan dalam kegiatan ini yaitu : a. Melakukan kegiatan 
observasi permasalahan dan mitra yakni pengabdi langsung datang ke lokasi mitra pengabdian untuk memperolah data. Hal tim lakukan pada saat menjelang maupun saat kegiatan berlangsung. Observasi berguna untuk mengetahui kondisi permasalahan yang ada dan sumber daya yang dapat dimanfaatkan dalam melakukan kegiatan. b. Melakukan kegiatan pengabdian masyarakat dengan sistem daring dalam pemberian materi kegiatan pengabdian masyarakat. c. Melakukan evaluasi dan shering bersama untuk menemukan kesepakatan bersama dalam melakukan perbaikan lingkungan.

\section{HASIL DAN PEMBAHASAN}

\section{A. Hasil Kegiatan}

Kegiatan pengabdian masyarakat dilaksanakan pada hari kamis, tanggal 27 Mei 2021 pada jam $09.00 \mathrm{~s} / \mathrm{d} 11$. 00 WIB dengan memanfaatkan program Zoom meeting. Kegiatan pengabdian masyarakat ini dilakukan guna membagikan informasi mengenai pemanfaatan bigdata dimana sekarang ini menggambarkan peralihan atau pergantian informasi dari 4.0 menjadi 5.0 merupakan teknologi informasi sosial sangat penting. Jauh hari saat sebelum aktivitas pengabdian akan dilaksanankan, kami tim pengabdian sudah merancang perencanaan kegiatan ini dengan matang supaya kegiatannya dapat berjalan dengan lancar serta dapat sukses dengan baik. Hal itu dilakukan supaya apa yang diharapkan ataupun yang jadi tujuan dari kegiatan pengabdian ini bisa tercapai. Rancangan perencanaan dimulai dengan melaksanakan pengkajian bersumber pada analisis kebutuhan serta bersumber pada permasalahan pada mitra.

Kegiatan pengabdian masyarakat ini dihadiri oleh 20 Orang peserta yang berasal dari mahasiswa budidaya pertanian Politeknik Kelapa Sawit Citra Widya Edukasi Bekasi. Dalam melaksanakan kegiatan pengabdian masyarakat tim pengabdi melaksanakan sebagian kegiatan berbentuk kegiatan pemberian informasi mengenai bigdata, pemanfaatan bigdata serta kasus yang terjadi dalam pemanfaatan bigdata ( latar belakang ) digunakan dalam bidang pendidikan, pertanian dan literasi. Kegiatan pengabdian yang sudah dilakukan diharapkan memberikan sesuatu manfaat untuk mahasiswa yang hendak terjun kedalam masyarakat mengenai perkembangan teknologi pada 5.0.

\section{B. Pembahasan}

Adapun hasil kegitan pengabdian masyarakat yang sudah dilakukan diperoleh hasil sebagai berikut :

1. Dalam melakukan kegiatan pengabdian warga kami tim pengabdi membagi beberapa kegiatan serta pembicara ataupun pelaksana kegiatan . Adapun kegiatan pengabdian masyarakat dan para pembicara atau pelaksana kegiatan yakni sebagai berikut : a. Pembukaan serta sambutan kegiatan pengabdian masyarakat ialah Luluk Setyowati, M.Pd. Selaku Ketua Pengabdian Masyarakat. b. Presentasi mengenai pemanfaatan bigdata dalam bidang pendidikan, pertanian dan literasi, pembicara atau pelaksana kegiatan ialah Deni Nasir Ahmad, M.Pd. Kegiatan presentasi berisikan mengenai teknologi pada era 5.0 ialah mengenai perkembangan teknologi era 5.0 barupa pengumpulan informasi yang berkaitan dalam pengumpulan data literasi. Perkembangan pada era 5.0 diawali dari tahun $2018 \mathrm{~s} / \mathrm{d}$ saat ini di Indonesia memberikan peran perubahan yang sangat besar, oleh karenanya dibutuhkan keahlian dasar yang wajib dipunyai mahasiswa dalam menjajaki zaman. Lebih lanjut, mengenai pembahasannya akan disampaikan narasumber serta berikutnya dapat dilakukan diskusi . 

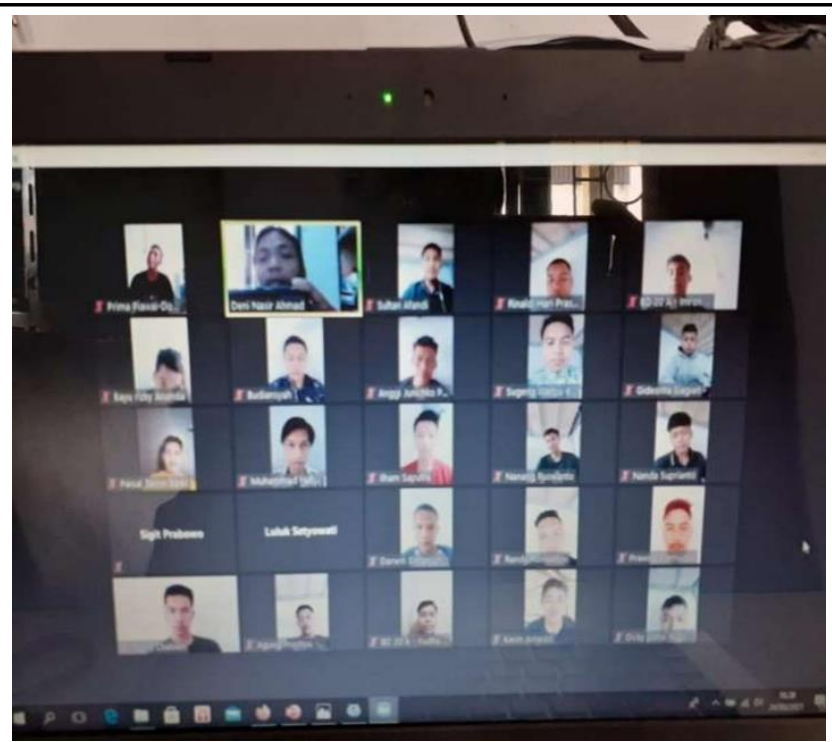

Gambar 1. Foto Kegiatan Dengan Zoommeating

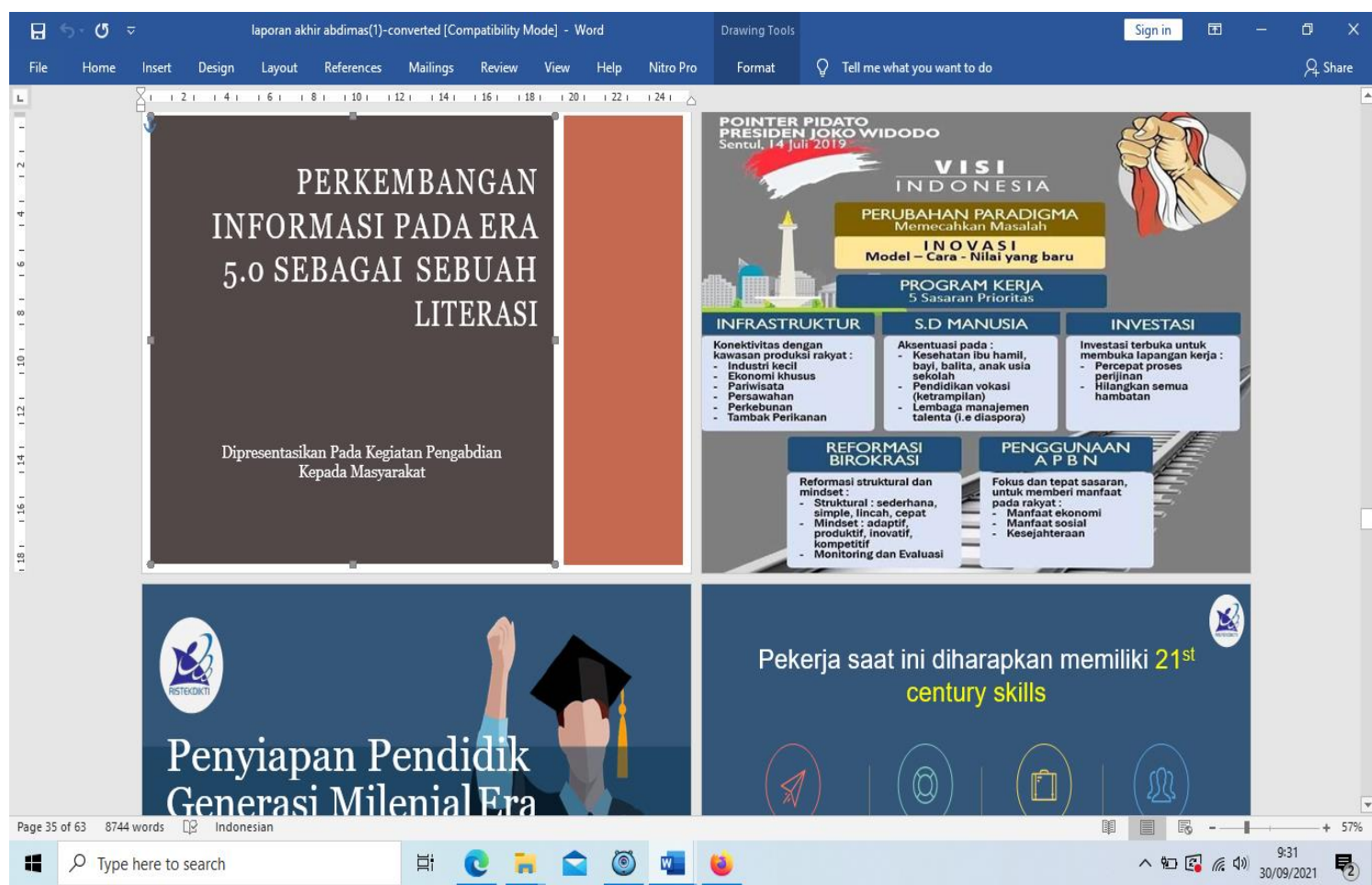

\section{Gambar 2. PPT Presentasi Kegiatan}

2. Para peserta yang terdiri dari mahasiswa calon pengelolaan pertanian dan teknologi pertanian Politeknik Kelapa Sawit Citra Widya Edukasi-Bekasi. Secara proaktif melakukan segala aktivitas dari awal hingga akhir. Rasa keingintahuan dan antusias dari para peserta membuat pemateri ataupun pembicara dalam melakukan kegiatan pengabdian masyarakat mendapatkan banyak informasi serta pengalaman dan rekomendasi dalam pengelolaan bigdata bidang pendidikan, pertanian dan literasi.

3. Dalam melaksanakan kegiatan pengabdian kepada mitra pengabdi, tim sangat berterima kasih kepada seluruh kalangan khususnya para peserta kegiatan telah bersedia membuka dirinya guna menerima informasi mengenai teknologi bigdata pada era 5.0 


\section{KESIMPULAN}

Adapun hasil dari kegiatan pengabdian masyarakat yang sudah dilaksanakan dapat disimpulkan sebagai berikut: a. Dalam melakukan kegiatan pengabdian masyarakat kepada mitra pengabdi, tim pengabdi mendapatkan banyak masukan dari peserta mengenai teknologi informasi bigdata 5.0 pada bidang pendidikan, pertanian dan literasi. b. Peserta pelatihan sangat berantusias serta proaktif dalam segala aktivitas dari awal hingga akhir kegiatan, terbukti bahwa banyaknya pertanyaan yang saling membangun guna meningkatkan hajat hidup banyak orang dalam bidang pendidikan, pertanian serta literasi. Perkembangan informasi 5.0 menggambarkan dasar peningkatan perekonomian masyarakat guna menuju masyarakat modern.

\section{DAFTAR PUSTAKA}

Agustini, R. \& Sucihati, M., 2020. Penguatan Pendidikan Karakter melalui Literasi Digital sebagai Strategi menuju Era Society 5.0. Prosiding seminar nasional pendidikan program pascasarjana universitas PGRI palembang, pp.999-1015.

Desyanti, D., Sri Handayani, S., Febrina, W. and Sari, F. (2021) "Pelatihan Penggunaan

Aplikasi Data Bahan Kimia Pada Smk Taruna Persada Dumai (Jurusan Laboratorium Kimia Smk Taruna Persada)", ABDINE: Jurnal Pengabdian Masyarakat, 1(1), pp. 26-33. doi: 10.52072/abdine.v1i1.170.

Ellitan, L., 2020. Competing in the Era of Industrial Revolution 4.0 and Society 5.0. Jurnal Maksipreneur: Manajemen, Koperasi, dan Entrepreneurship, 10(1), p.1.

Gellysa Urva, Pratiwi, M. \& Oemara Syarief, A., 2021. E-Learning berbasis Edmodo untuk Optimalisasi Pembelajaran Pada Masa New Normal. ABDINE: Jurnal Pengabdian Masyarakat, 1(1), pp.41-47.

Hendarsyah, D., 2019. E-Commerce Di Era Industri 4.0 Dan Society 5.0. IQTISHADUNA: Jurnal Ilmiah Ekonomi Kita, 8(2), pp.171-184.

Ma'rifatullah, S. et al., 2020. Workshop Pembelajaran E-Learning di Era Society 5.0. Jurnal Ilmiah Pangabdhi, 6(2), pp.163-167.

Marlinah, L., 2019. Pentingnya Peran Perguruan Tinggi dalam Mencetak SDM yang Berjiwa Inovator dan Technopreneur Menyongsong Era Society 5.0. Jurnal IKRAITH Ekonomika, 2(3), pp.17-25.

Muhammad Yahya, H., 2018. ERA INDUSTRI 4.0: TANTANGAN DAN PELUANG PERKEMBANGAN PENDIDIKAN KEJURUAN INDONESIA Disampaikan pada Sidang Terbuka Luar Biasa Senat Universitas Negeri Makassar Tanggal 14 Maret 2018.

Mumtaha, H.A. \& Khoiri, H.A., 2019. Analisis Dampak Perkembangan Revolusi Industri 4.0 dan Society 5.0 Pada Perilaku Masyarakat Ekonomi (E-Commerce). JURNAL PILAR TEKNOLOGI: Jurnal Ilmiah Ilmu Ilmu Teknik, 4(2), pp.55-60.

Puspita, Y. et al., 2020. Selamat Tinggal Revolusi Industri 4.0, Selamat Datang Revolusi Industri 5.0. Prosiding Seminar Nasional Pendidikan Program Pascasarjana Universitas Pgri Palembang, pp.122-130. 